\title{
CFD and Laboratory Studies of Dust Cleaning Efficacy of an Efficient Four Stage Non-Clogging Impingement Filter for Flooded-Bed Dust Scrubbers
}

Ashish Ranjan Kumar ( $\sim$ ashish.kumar@uky.edu )

Missouri University of Science and Technology https://orcid.org/0000-0002-8611-8346

Neeraj Gupta

University of Kentucky College of Engineering

Steven Schafrik

University of Kentucky College of Engineering

\section{Research}

Keywords: Dust filter, Computational fluid dynamics modeling, Iso-kinetic sampling, Optical particle counting, Flooded-bed dust scrubber

Posted Date: August 9th, 2021

DOI: https://doi.org/10.21203/rs.3.rs-757559/v1

License: (c) (i) This work is licensed under a Creative Commons Attribution 4.0 International License. Read Full License 


\section{Abstract}

Fibrous-type filters are used to capture dust particles in mining and other occupations where personnel are exposed for prolonged periods. Dust cleansing systems including flooded-bed dust scrubbers use these mesh-type multi-layered filters. These filters trap dust particles efficiently on their surface and inside their mesh. However, their continued operation leads to dust build-up and subsequent clogging. This results in increased resistance of the filter and lowered airflow rate through the scrubber. This could potentially enhance the exposure of the miners. A non-clogging self-cleaning impingement screen type dust filter was designed by the authors for use in mining and industrial dust cleansing applications. The filter guides dirt-laden air through rapidly turning paths which forces it to shed heavier particles. The particles impact one of the impermeable solid metallic filter surfaces and are removed from the airstream. A full cone water spray installed upstream prevents any surface build-up of dust. This paper summaries the computer models generated to show the filter operations and laboratory experiments including optical particle counting to establish the cleaning efficiency.

\section{Highlights}

- CFD models were generated to demonstrate particle-laden fluid flow.

- Particle tracking models were developed for different dust diameters.

- An iso-kinetic sampling of coal/limestone dust particles was performed.

- Filtration efficiency was computed using the gravimetric concentrations.

\section{Introduction}

Many unit operations in mining generate respirable dust and their concentration varies significantly across all those processes (Petavratzi, et al., 2005). This includes mechanical excavation, handling and transportation, and crushing. Respirable coal and rock dust particles could be inhaled and travel into the lungs. These particles get deposited on the lung surface and impede nominal breathing. Prolonged exposure to respirable dust has been conclusively shown to cause irreversible ailments in miners (Joy, et al., 2012; Laney \& Weissman, 2014). Coal dust accumulation beyond critical concentration has also resulted in explosion events in underground mines leading to fatalities and loss of operations (Mine Safety and Health Administration, 2001; Mine Safety and Health Administration, 2014). Mine operators, therefore, use a wide variety of remedial measures to combat dust. Primarily, fresh air is sent underground to dilute the dust concentration to lower levels via ventilation systems. Water sprays effectively direct the dust-laden air away from the miners. Underground mines also use physical barriers to protect them from elevated dust levels. Underground operations including continuous miner sections use a combination of these methods. Continuous miners have an onboard fan-powered flooded-bed dust scrubber that treats the coal dust-laden air close to the active face (Colinet, et al., 2013). The scrubber has an inlet that captures the dirty air close to the miner drum. A multi-layered fibrous type dust filter is the primary cleaning element that traps dust particles on its undulating surface (Gupta, et al., 2021). A water 
spray is installed upstream of the filter and mounted at $45^{\circ}$ to the airflow direction to keep the filter surface drenched and prevent any build-up. Cleansed air is discharged after traveling through a demister which removes water droplets from the air. Wet scrubbers were also developed in the 1970s and could capture solid and liquid particles efficiently (Eckert \& R.F. Stringle, 1974).

Research on 20-layered fibrous-type dust filters showed that the cleaning efficiency of the filter improved with an increase in airflow and water flow through the filter (Kumar, 2018; Velasquez, 2019). Fibrous filters, however, get clogged during operations leading to dust build-up (Thomas, et al., 2001). This increases the filter resistance and lowers the airflow (Kanaoka \& Hiragi, 1990). A study by Song et al. using monodispersed polystyrene latex particles showed that initial particle collection occurs inside the filter bed. Filter resistance increases with clogging and filtration tends to occur on the front edge (Song, et al., 2006). Yue et al. studied the filtration process through random three-dimensional fibrous filters using computational fluid dynamics modeling and discrete element methods. They showed that particles were initially captured by the fibers. The filtration process led to blockage by deposited particles which increased the resistance (Yue, et al., 2016). Agranovski and Shapiro studied the clogging process due to dust particles in wet and dry filters. They observed that the resistance of the dry filtration process was about half of the wet filtration resistance. Non-wettable filters were also found to get rapidly blocked (Agranovski \& Shapiro, 2001). Computer models have shown that the compressibility of aerosol particles has a significant impact on filter clogging with trapped compressible particles leading to early filter replacement (Stöcklmayer \& Höflinger, 1998). Experimental studies on filter media used in industrial air cleaning by Callé et al. showed that the filtration efficiency of the media increased during the collection phase and diminished in the cleaning phase. The residual pressure drop was also found to increase overloading and cleaning cycles (Callé., et al., 2002). Research by Japuntich et al. showed that filter loading by different size particles contributes to pressure drop on all stages of loading (Japuntich, et al., 1994). Laminger et al. developed mathematical models to demonstrate an increase in residual pressure drops over cycles of filtration and regeneration operations. The model assumed the particle deposition area on the filter as a significant factor that governed the filtration mechanism (Laminger, et al., 2016). Fotovati et al. generated numerical models for pleated filters, which are also used most in industrial applications, and showed that pressure drop is minimum for an optimum pleat count. Triangular pleats were also found to result in a lower pressure drop (Fotovati, et al., 2011). The airflow capture efficiency of the clogged filter, in all the cases discussed here, is diminished which might lead to an elevated exposure of the miners to dust. Therefore, research to develop non-clogging efficient dust filters is critical to enhancing the health of miners and the safety of operations.

Filters that do not use fibrous type irregular mesh type filters could be efficient alternatives and the dust particles are made to follow a pre-defined trajectory and guided towards impermeable surfaces where they could be trapped. This follows the mechanism of particle impactor systems, designed by Marple in the 1960s, frequently used for particle size classification and analysis (Marple \& Willeke, 1967). These devices force air between parallel plates with slits. This change in direction forces aerosol particles to be cast out and hit the plates where they are trapped. The spacing within successive plates also diminishes 
which assists in capturing smaller particles on the plates downstream. Impingement-type filters are also very efficient in capturing aerosol particles (Dahneke, 1971).

There has not been significant research in this area leading to industrial applications in mining or similar industries that deal with dust exposure. A self-cleaning bar-type screening unit working on a vibrating mechanism was patented in 1969. This was designed to screen silica particles measuring 325 mesh (0.004 in.) size (Pearsali, 1969). Higginbotham was granted a patent in 2007 for his invention of a nonclogging screen filter, though it was designed to prevent clogging of sewage systems and dealt with large particles (Higginbotham, 2007). Cyclone-type scrubbers were also studied and found to be efficient in removing particles from the airstream (Krames \& Buttner, 1994). The University of Kentucky designed Vortecone to capture overspray paint particles of size up to $300.0 \mu \mathrm{m}$ on automobile painting lines (Tanigawa, et al., 2008). A reduced scale model of the Vortecone was tested and its excellent efficiency in capturing coal dust particles from the airstream was established (Kumar, et al., 2019; Kumar \& Schafrik, 2020; Kumar, et al., 2020). Parametric studies of geometrical features were carried out to redesign the filter later to lower the resistance and to improve its dust-laden air capture efficiency (Taylor, et al., 2019). However, the vortex-type complex design of the Vortecone would require a thorough redesign of systems. A flooded-bed dust scrubber could use the proposed thin filter as an alternative to the fibrous filter. Preliminary research on a reduced-scale prototype of an impingement filter showed its efficacy (Kumar, et al., 2020). The authors have designed and investigated the performance of a four-screen filter with perforated staggered openings to remove particles from the airstream. This paper describes the design and performance testing of the non-clogging filter using computational fluid dynamics modeling and laboratory testing using optical particle counting.

\section{Filter Description}

A four-stage filter with $1.5 \mathrm{~mm}$ thick flat impingement screen surfaces was designed. All screens had long rectangular openings $6.0 \mathrm{~mm}$ in width and $78.0 \mathrm{~mm}$ in length. The first and third screen surfaces are identical in design. The second and the fourth surfaces are identical and have their rectangular openings displaced in the screen plane by $6.0 \mathrm{~mm}$. Filter surfaces were separated by spacers measuring 3.0, 2.0, and $3.0 \mathrm{~mm}$ in length, respectively. The total thickness of the filter, therefore, is $14.0 \mathrm{~mm}$. This configuration makes the filter perfectly blind to straight flows. Dust-laden air is forced to follow constricted turns between all the filter surfaces. Heavier dust particles are drawn out of the airstream due to their inability to change directions suddenly. These particles impact the filter surfaces due to much higher momenta and are removed from the air stream. The filter will be installed at $45^{\circ}$ to the general airflow direction. The physical prototype of the filter is shown in Fig. 1. Airflow patterns are shown in the following paragraphs.

\section{Computational Fluid Dynamics Modeling}

Computation fluid dynamics (CFD) modeling analysis was done to optimize the performance parameters as the geometrical dimensions were altered iteratively during the design stage. CFD modeling is a flow 
volume discretization technique wherein the Navier-Stokes equations of fluid dynamics are solved using numerical approximation. ANSYS Fluent software, version 18.2 was used to generate the CFD models. The structure of the flow domain was drawn in AutoCAD and imported into ANSYS Fluent. The integrity of the fluid flow region was ascertained in the design modeler module. Inlet and outlet segments were demarcated and assigned unique names. A vertical symmetry plane was drawn to bifurcate the flow volume. This created a much smaller analysis region, saved on computing resources, and allowed the generation of fine meshes to resolve the airflow patterns around the filter. Figure 2 shows the geometry used for analysis.

Boundary conditions for this setup included flux and wall functions. The inlet surface was assigned a normal velocity value of $3.80 \mathrm{~m} / \mathrm{s}$. Corresponding turbulence intensity and turbulence viscosity values were computed. The outlet surface was imparted a static pressure of $0.0 \mathrm{~Pa}$. Surfaces of the symmetry planes were assigned free-slip symmetry plane conditions while all other surfaces were imparted wall functions.

The SIMPLE scheme was used for pressure-velocity coupling. The least-squares cell-based gradient calculation method was followed.

\subsection{Meshing and grid independence studies}

The multi-zone method meshing technique was followed and the flow domain was split into three connected volumes. The volume around the filter had tetrahedral elements while the ones towards the inlet and the outlet had polyhedral elements. This enabled a high resolution of flow close to the filter and saved on element count. A dense mesh was a prerequisite since micron-size dust particles had to be tracked in the transient-state simulations later to determine the particle removal efficiency. Three meshes with increasing packing density were generated. The meshes had about 10.98, 15.72, and 21.84 million grid elements. The total pressure drop was computed for an incoming airspeed of $3.80 \mathrm{~m} / \mathrm{s}$. Microsoft Excel solver was used to compute absolute and relative errors. The mesh parameters are shown in Table 1. Extrapolated errors in velocity and fine grid convergence indices were computed using Richardson's method and are shown in Table 2.

Relative, extrapolated, and fine grid convergence index decreases with an increase in grid packing density indicating good grid convergence. The second mesh with 15.72 million elements was used for further simulations. CFD models were generated on windows based high-performance computer.

\subsection{Steady and transient-state simulations}

Steady-state simulations were run until the solution converged according to the pre-assigned conditions. 
Table 1

Parameters to demonstrate grid-independence studies

\begin{tabular}{|llll|}
\hline Parameter & Mesh 1 & Mesh 2 & Mesh 3 \\
\hline Element count (million) & 10.98 & 15.72 & 21.84 \\
\hline Average cell height $(\mathrm{mm})$ & 2.41 & 2.13 & 1.91 \\
\hline The pressure at the inlet $(\mathrm{Pa})$ & 277.00 & 278.50 & 278.70 \\
\hline
\end{tabular}

Table 2

Computed errors for grid independence

\begin{tabular}{|lll|}
\hline Parameter & Meshes 1 and 2 & Meshes 2 and 3 \\
\hline Approximate relative error (\%) & 0.54 & 0.07 \\
\hline Extrapolated pressure (Pa) & 286.07 & 279.62 \\
\hline Extrapolated error in pressure (\%) & 2.65 & 0.33 \\
\hline Fine grid convergence index & 3.41 & 0.41 \\
\hline
\end{tabular}

Models were generated and run until convergence in flow parameters was achieved. Figure 3 shows the contours of velocity magnitude on a plane in the flow domain for an airflow rate of $0.71 \mathrm{~m}^{3} / \mathrm{s}$. Air was observed to accelerate between the filter surfaces which will assist in forcing particles towards one of the surfaces leading to their capture. Steady-state simulations were run for different airflows and corresponding total pressure drops were computed. These were compared to the pressure drop obtained in the laboratory experiments and were found to be in excellent agreement as discussed later.

Transient-state simulations were developed to determine the profile of particles' sizes that impact the filter surface under known airflows. An array of spherical aerosol particles of known diameters adjusted using Cunningham's slip correction factor was generated at the domain inlet for $0.10 \mathrm{~s}$ (Cunningham, 1910). An initial velocity was assigned to the particles based on the average airflow rate through the filter. Particles were tracked for a period of $1.00 \mathrm{~s}$. The filter surfaces were programmed to trap the particles. Particles underwent an inelastic collision with all other surfaces with a coefficient of restitution value of 0.95. Particles were counted on the inlet and the filter surface. These particle counts were used to compute the particle removal efficiency of the filter from the air. These results are included along with the results obtained from laboratory testing.

\section{Experimental Setup And Procedure}

Filter resistance and cleaning efficiency are the two critical parameters that define its performance. A prototype made of aluminum was constructed to determine these parameters and to validate the computer models. Spacers measuring 3.0, 2.0, and $3.0 \mathrm{~mm}$ were used to separate the successive flat filter surfaces. The filter measured $14.0 \mathrm{~mm}$ in thickness. 
A test set up as shown in Fig. 4 was constructed. The experimental set-up consisted of a system of ducts with a centrifugal fan attached to it. The fan was operated using a variable frequency drive (VFD) that enabled setting up any airflows precisely. The duct measured $0.30 \mathrm{~m} \times 0.45 \mathrm{~m}$ in cross-section and was $2.40 \mathrm{~m}$ in length to allow a well-developed flow profile. This was followed by a Dwyer pressure measurement station used to obtain total and static pressures in the duct. This also had honeycomb-like structures that served as the flow straighteners. Vane and rail arrangements were built around the corners to encourage a good airflow profile and to minimize the shock losses. The filter was installed downstream of the bend in a duct with an identical cross-section area and length. A $1.20 \mathrm{~m}$ long duct was built with transparent polycarbonate sheets to install the filter at $45^{\circ}$ to the airflow direction like a floodedbed dust scrubber set up. All lines of contact were sealed to prevent any leakages. A full cone water spray was installed upstream of the filter to inject water normal to the filter plane as shown in Fig. 5. A flow control valve and an inline digital flowmeter were installed in series to control the water flow rate precisely.

\subsection{Steady-state testing in the dry state}

Tests were first run to determine the filter resistance. VFD frequency was set at $10.0 \mathrm{~Hz}$ and increased in steps of $5.0 \mathrm{~Hz}$. Total and static pressure at different airflows were measured. Velocity pressure was calculated and was used to determine the airflow through the filter. These steps were repeated three times to obtain a good representative average. A curve of best fit through these points was drawn as shown in Fig. 6 that represents the flow-pressure drop curve showing a quadratic dependence of pressure drop on volumetric flow rate for the filter. Filter resistance using this curve was obtained to be $1.675 \mathrm{kNs}^{2} / \mathrm{m}^{8}$. An adjusted $R^{2}$ value of 0.9998 , a standard error value of 0.0034 , and a t-value of 496.82 indicate an excellent fit.

Once the fan system curve was constructed, the duct discharge was connected to the dust exhausting system of the laboratory to minimize exposure of the researchers to coal dust particles while running cleaning efficiency experiments. Velocity in the duct was computed again with the water spray running using the pressure measurement station to determine the airflow through the filter.

\subsection{Isokinetic sampling for aerosols}

Two identical TSI optical particle sizers (OPS 3330) were used for airflow sampling. Air was sampled isokinetically upstream and downstream of the filter. This is a technique in which aerosol particles are extracted from the airstream without altering the airflow speed in the vicinity of the sampling nozzle (Wilcox, 1956). If not done properly, this could lead to under-sampling or over-sampling of the aerosol particles leading to inaccurate results. Sampling nozzles were designed, and 3D printed for airflows of $0.47,0.71$, and $0.94 \mathrm{~m}^{3} / \mathrm{s}$ in the duct.

Keystone Mineral Black $325 \mathrm{~A}$ and limestone particles were used to study the cleaning efficiency of the dust filter. This coal dust specimen has a known particle size distribution and has been used to investigate scrubber performance earlier. 
This coal dust specimen has a known particle size distribution and has been used to investigate scrubber performance earlier. An Arduino-controlled stepper motor-assisted dust injection system was built to inject dust upstream of the filter. TSI optical particle sizer (OPS) 3330 device was used to count and size the aerosol particles. Densities of coal $\left(1,220 \mathrm{~kg} / \mathrm{m}^{3}\right)$ and limestone dust $\left(2,200 \mathrm{~kg} / \mathrm{m}^{3}\right)$ were programmed in the OPS. The complex refractive index of coal $(1.76-i 0.60)$ and limestone $(1.50-i$ $0.005)$ were programmed to run experiments with suitable particles. The dead time correction parameter was enabled to minimize errors due to coincidence due to many particles in the sample. Dust particles were injected into the pressurized duct using compressed air. A sensitive digital weighing balance was used to precisely measure $3.2 \mathrm{gm}$ of coal dust and $3.5 \mathrm{gm}$ of limestone dust for each run of the tests. Dust particles were introduced into the duct for 5.0 minutes. The controlled injection of dust particles into the duct ensured that none of the OPSs was overwhelmed with dust particles. This effectively eliminated the coincidence error which would have resulted in an incorrect particle count and size. Iso-kinetic sampling nozzles were designed with dimensions computed using airflow velocity magnitudes, 3D printed and attached to the tube. The duct was traversed precisely to locate points where the average airflow speed equaled the speed reported by the pressure measurement station.

\subsection{Cleaning efficiency results}

Particle concentration by count data obtained from the two OPSs installed upstream and downstream of the filter were converted into gravimetric concentrations using the aerosol instrument manager software. Figure 7 shows one such plot of the gravimetric concentration of coal dust particles upstream and downstream of the filter for an airflow of $0.94 \mathrm{~m}^{3} / \mathrm{s}$. The difference in gravimetric concentration upstream and downstream of the filter is the cleaning efficiency under the operating conditions. These were computed for particle sizes $2.00 \mu \mathrm{m}$ and above for the three airflows. Figure 8 shows the cleaning efficiency of the impingement filter for coal dust particles. The plot shows that the efficiency of the removal of dust particles from the airstream increases with an increase in airflow through the filter. Bigger and heavier particles are removed significantly more compared to the smaller particles that tend to follow the airstreams and might escape the filter.

Figure 9 shows the cleaning efficiency using limestone particles. Water flow was kept steady at 7.57 $\mathrm{I} / \mathrm{min}(2.0 \mathrm{gpm})$ for these tests. The impingement type filter captured removed bigger particles. Figure 10 compares the particle removal efficiency from the air obtained from transient-state CFD models and laboratory experiments. The computer models agree well with the laboratory testing results.

Figure 10: Comparision of cleaning efficiency of CFD models and laboratory test

\section{Conclusions}

Micron size dust particles produced in mining and other industries are detrimental to the health of the workers and the safety of the operations. These industries use fibrous-type dust filters to capture dust particles. These are efficient over a wide range of particle diameters. However, these are maintenance intensive and get clogged due to particles getting caught on the surface and inside the fibrous layers. 
This enhances the filter resistance, increases the pressure drop, and leads to a much lower volume of air being cleaned. This severely affects the operational efficiency of the machines using these filters.

A non-clogging filter was designed based on the aerosol particle impaction principle. The filter has 6.0 $\mathrm{mm}$ wide and $78.0 \mathrm{~mm}$ long openings. These large openings allow the impingement filter to clean the dirt-laden air without the need for any maintenance arising out of clogging, unlike the conventional fibrous filters that tend to get clogged rapidly. Particles are removed from the dust-laden air by forcing them to negotiate sharp bends. At higher airflows, high momentum possessed by the particles casts them out of the airstream and forces them to impact one of the screen surfaces. The inability of the heavier particles to change directions suddenly leads to their removal from the air stream. The non-clogging nature of the filter ensures that there will not be any cyclic jump in pressure drop due to filter clogging as observed in all fibrous filters. Therefore, this filter will continue to operate at a known point for prolonged periods. This design also allows engineers to design an impingement type filter for a known airflow rate or to maximize the capture of particles of a specific size. This filter also does not require a high water flow rate, unlike the fibrous filter in which the fibrous surface is required to be kept flooded to capture the particles efficiently. So, the flow rate was kept constant at a relatively low value of $7.57 \mathrm{l} / \mathrm{min}(2.0 \mathrm{gpm})$.

Since this filter works on the particle impaction principle, its cleaning efficiency will improve further at higher airflows. Denser aerosol particles will also be removed more efficiently due to higher mass and momentum. The dimension of the openings, their separation, and screen spacings impact the pressure drop and cleaning efficiency at known airflows. Since the impingement filter will not get clogged, need minimal maintenance, and will have higher mechanical availability. These filters could be designed for known airflows and can be a good replacement to the conventional fibrous filters in mining operations.

\section{Declarations}

\section{Funding}

The authors acknowledge the National Institute for Occupational Safety and Health (NIOSH) for funding this research project. The research in contract \#75D30119C06228 'Maintenance-free filters for continuous miner scrubber' is aimed at the development of efficient filters for mining dust alleviation.

\section{Ethics Declaration}

The authors do not have any conflict of interests that could have impacted this research.

\section{References}

Agranovski, I. \& Shapiro, M., 2001. Clogging of wet filters by dust particles. Journal of Aerosol Science, 32(8), pp. 1009-1020. 
Callé., S. et al., 2002. Evolutions of efficiency and pressure drop of filter media during clogging and cleaning cycles. Powder Technology, 128(2-3), pp. 213-217.

Colinet, J., Reed, W. \& Potts, J., 2013. Impact of respirable dust levels when operating a flooded-bed scrubber in 20-ft cuts, Pittsburgh, Spokane: National Institute for Occupational Safety and Health.

Cunningham, E., 1910. On the velocity of steady fall of spherical particles through fluid medium. Proceedings of the Royal Society A: Mathematical, Physical and Engineering Sciences, 83(563), pp. 357365.

Dahneke, B., 1971. The Capture of Aerosol Particles by Surfaces. Journal of colloid and Interface Science, October, 37(2), pp. 342-353.

Eckert, J. \& R.F. Stringle, J., 1974. Performance of Wet Scrubbers on Liquid and Solid Particulate Matter. Journal of the Air Pollution Control Association, 24(10), pp. 961-966.

Fotovati, S., Hosseini, S., Tafreshi, H. \& Pourdeyhimi, B., 2011. Modeling instantaneous pressure drop of pleated thin filter media during filter loading. Chemical Engineering Science, 66(18), pp. 4036-4046.

Gupta, N., Kumar, A. R. \& Schafrik, S., 2021. Laboratory determination of coal dust cleaning efficacy of a fibrous filter for flooded-bed dust scrubber. Minerals, 11(3).

Higginbotham, E., 2007. Nonclogging screen. United States, Patent No. 7,174,688 B2.

Japuntich, D., Stenhouse, J. \& Liu, B., 1994. Experimental results of solid monodisperse particle clogging of fibrous filters. Journal of Aerosol Science, 25(2), pp. 385-393.

Joy, G., Colinet, J. \& Landen, D., 2012. Coal workers' pneumoconiosis prevalence disparity between Australia and the United States. Mining Engineering, June, 64(7), pp. 65-71.

Kanaoka, C. \& Hiragi, S., 1990. Pressure drop of air filter with dust load. Journal of Aerosol Science, 21(1), pp. 127-131.

Krames, J. \& Buttner, H., 1994. The cyclone scrubber - a high efficiency wet separator. Chemical Engineering and Technology, 17(2), pp. 73-80.

Kumar, A., 2018. Dust control examination using computational fluid dynamics modeling and laboratory testing of Vortecone and impingement filters, Lexington, KY: s.n.

Kumar, A. et al., 2019. Computational fluid dynamics modeling and laboratory analysis of aerosol particles' capture on thin swirling water film in a Vortecone. Powder Technology, Volume 361C, pp. 499506.

Kumar, A. R. \& Schafrik, S., 2020. Multiphase CFD modeling and laboratory testing of a Vortecone for mining and industrial dust scrubbing applications. Process Safety and Environmental Protection, Volume 
144 , pp. $330-336$.

Kumar, A. R., Schafrik, S. \& Novak, T., 2020. Multi-phase computer modeling and laboratory study of dust capture by an inertial Vortecone scrubber. International Journal of Mining Science and Technology, 30(3), pp. $287-291$.

Kumar, A. R., Schafrik, S. \& Velasquez, O., 2020. Designing, modeling, and laboratory testing of an impingement type filter for mining dust scrubbers. Mining, Metallurgy \& Exploration, Volume 37, pp. 19111918.

Laminger, T., Stecher, M., Mauschitz, G. \& Höflinger, W., 2016. Modeling the pressure drop behavior of cleanable dust filters during pressure-controlled operation. Separation Science and Technology, 52(18), pp. 2788-2794.

Laney, A. \& Weissman, D., 2014. Respiratory disease caused by coal mine dust. J Occup Environ Med, Oct, Volume 10, pp. 18-22.

Marple, V. \& Willeke, K., 1967. Impactor design. Atmospheric Environment, 10(10), pp. 891-896.

Mine Safety and Health Administration , 2001. Report of Investigation, Fatal Underground Coal Mine Explosions. s.I.:United States Department of Labor.

Mine Safety and Health Administration, 2014. Upper Big Branch Mine-South, Performance Coal Company. s.I.:United States Department of Labor.

Pearsali, R., 1969. Bar type screening unit with resilient edge sealing means. United States, Patent No. $3,483,974$.

Petavratzi, E., Kingman, S. \& Lowndes, I., 2005. Particulates from mining operations: A review of sources, effects and regulations. Minerals Engineering, Volume 18, pp. 1183-1199.

Song, C., Park, H. \& Lee, K., 2006. Experimental study of filter clogging with monodisperse PSL particles. Powder Technology, Volume 163, pp. 152-159.

Stöcklmayer, C. \& Höflinger, W., 1998. Simulation of the regeneration of dust filters. Mathematics and Computers in Simulation, 46(5-6), pp. 601-609.

Tanigawa, Y. et al., 2008. Development of a New Paint Over-Spray Eliminator. Lexington, s.n., pp. $325-341$.

Taylor, A., Schafrik, S. \& Kumar, A. R., 2019. The Vortecone: A new maintenance-free wet scrubber device. Sydney, NSW, The Australasian Institute of Mining and Metallurgy, pp. 216-228.

Thomas, D., Penicot, P., Contal, P. \& Vendel, J., 2001. Clogging of fibrous filters by solid aerosol particlesExperimental and modelling study. Chemical Engineering Science, 56(11), pp. 3549-3561. 
Velasquez, 0., 2019. Influence of water injection rate on the Vortecone, an impingement screen, and a conventional filter screen cleaning efficiency, Lexington, KY: s.n.

Wilcox, J., 1956. Isokinetic flow and sampling. Journal of the Air Pollution Control Association, 5(4), pp. 226-245.

Yue, C., Zhang, Q. \& Zhai, Z., 2016. Numerical simulation of the filtration process in fibrous filters using CFD-DEM method. Journal of Aerosol Science, Volume 101, pp. 174-187.

\section{Figures}
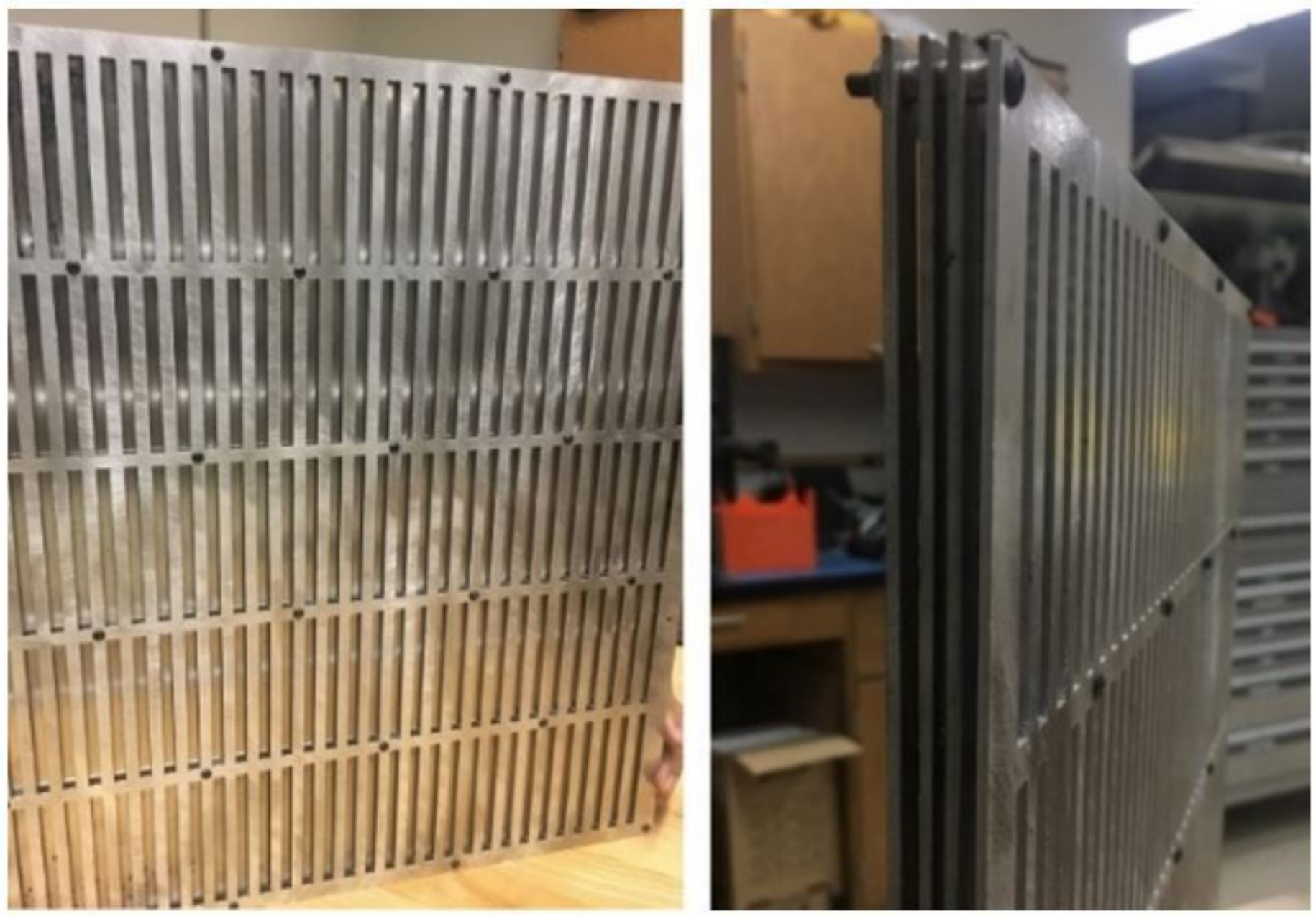

Figure 1

Design of the four-screen impingement filter 


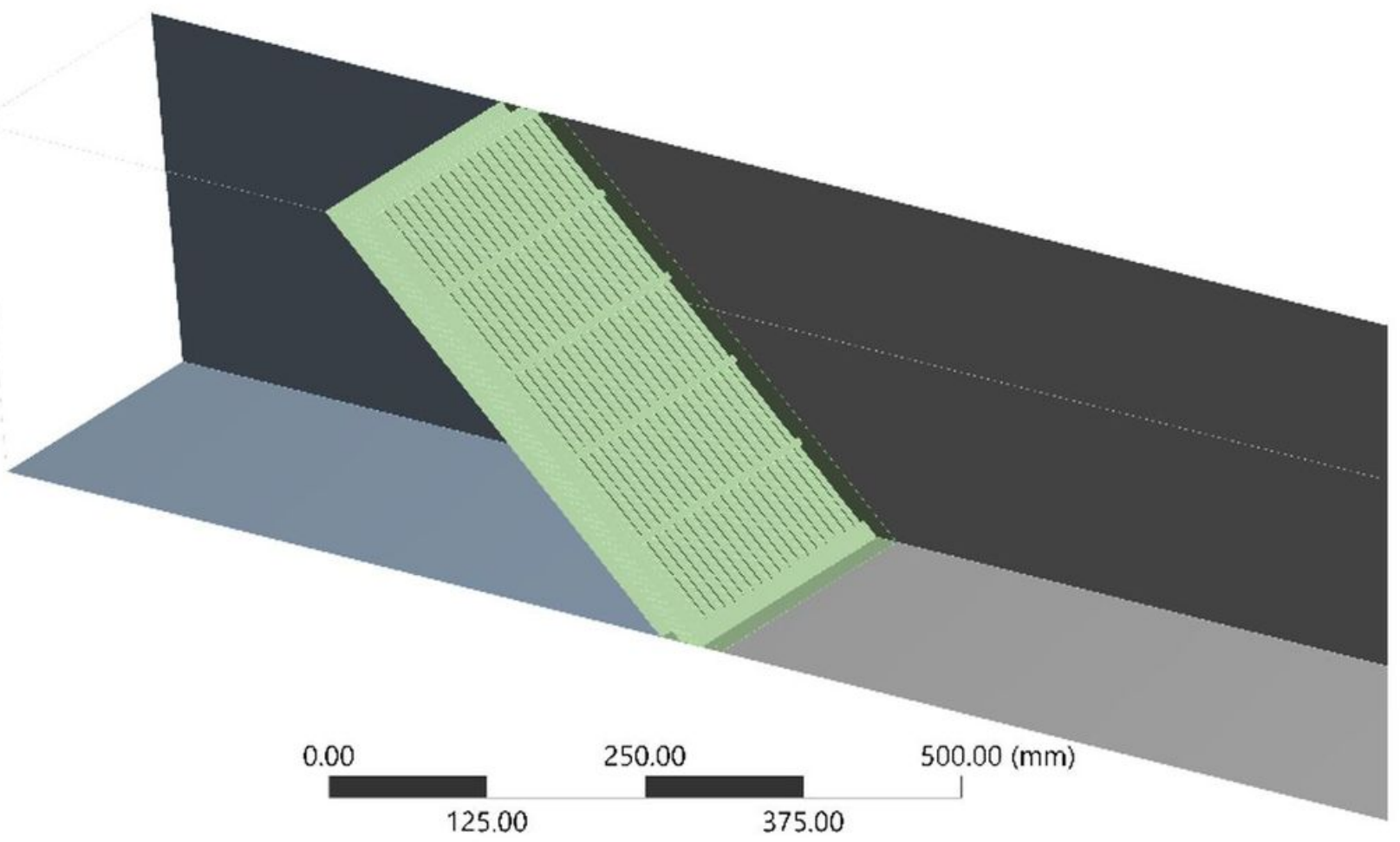

Figure 2

Geometry set up for computational fluid dynamics analysis

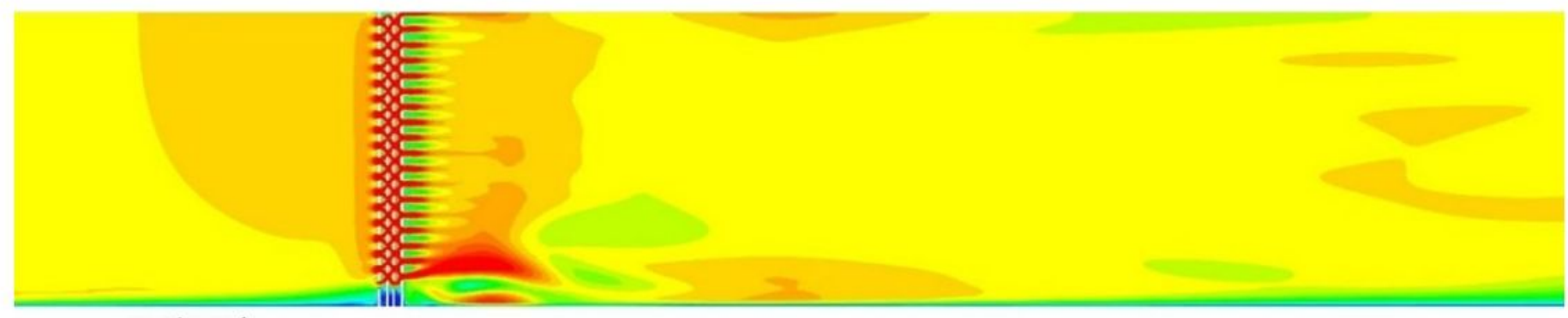

contour-1

Velocity Magnitude

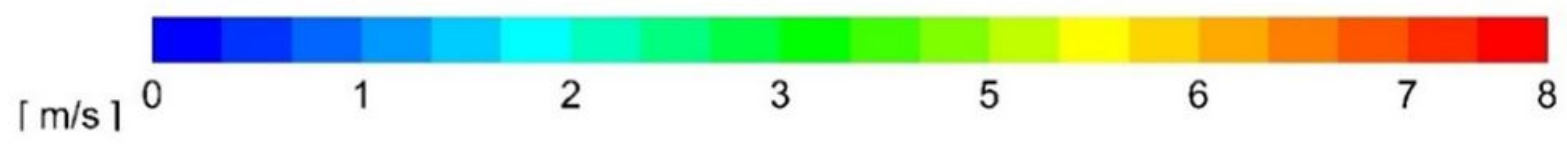

Figure 3

Contours of velocity magnitude at an airflow of $0.71 \mathrm{~m} 3 / \mathrm{s}$ 


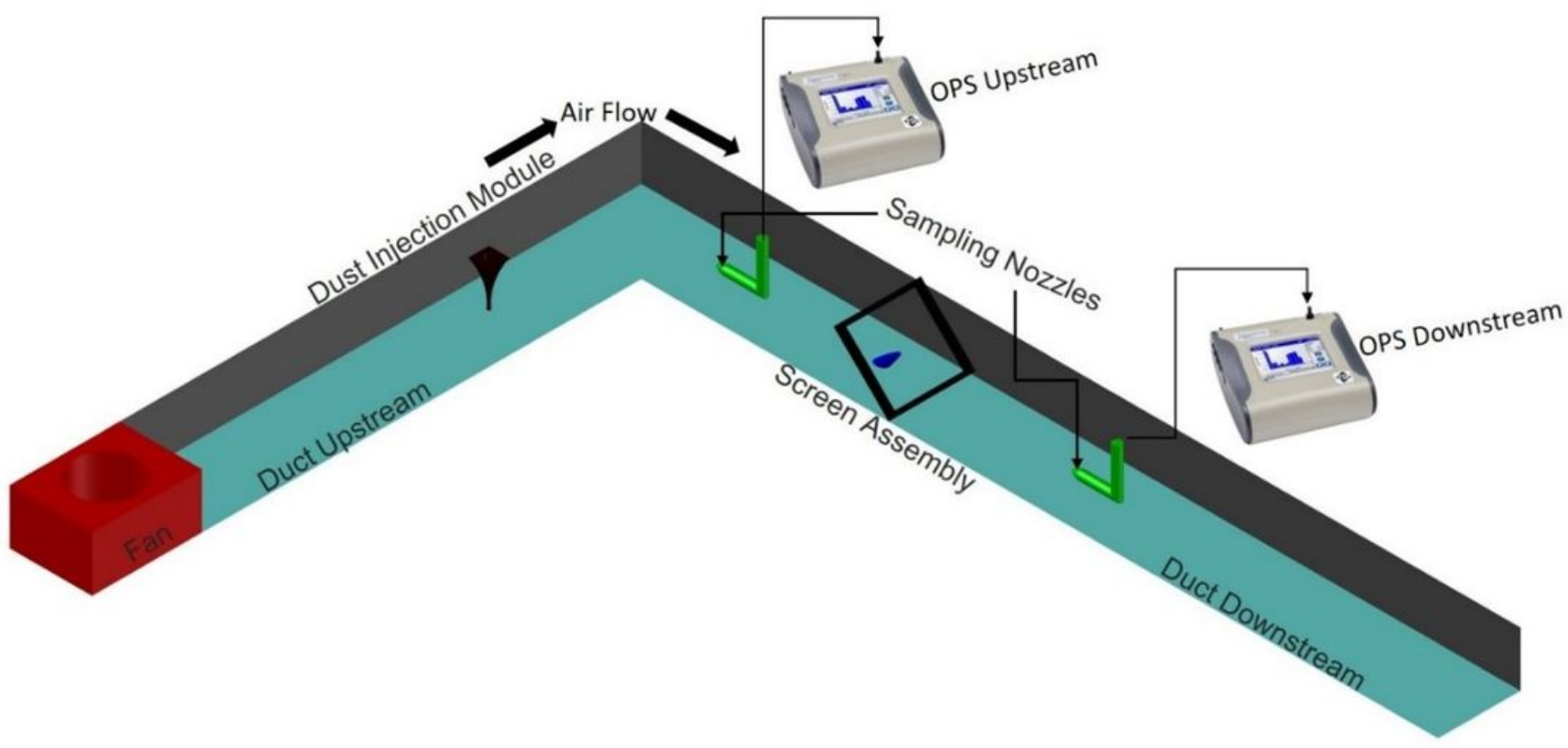

Figure 4

A schematic of the experimental set-up 


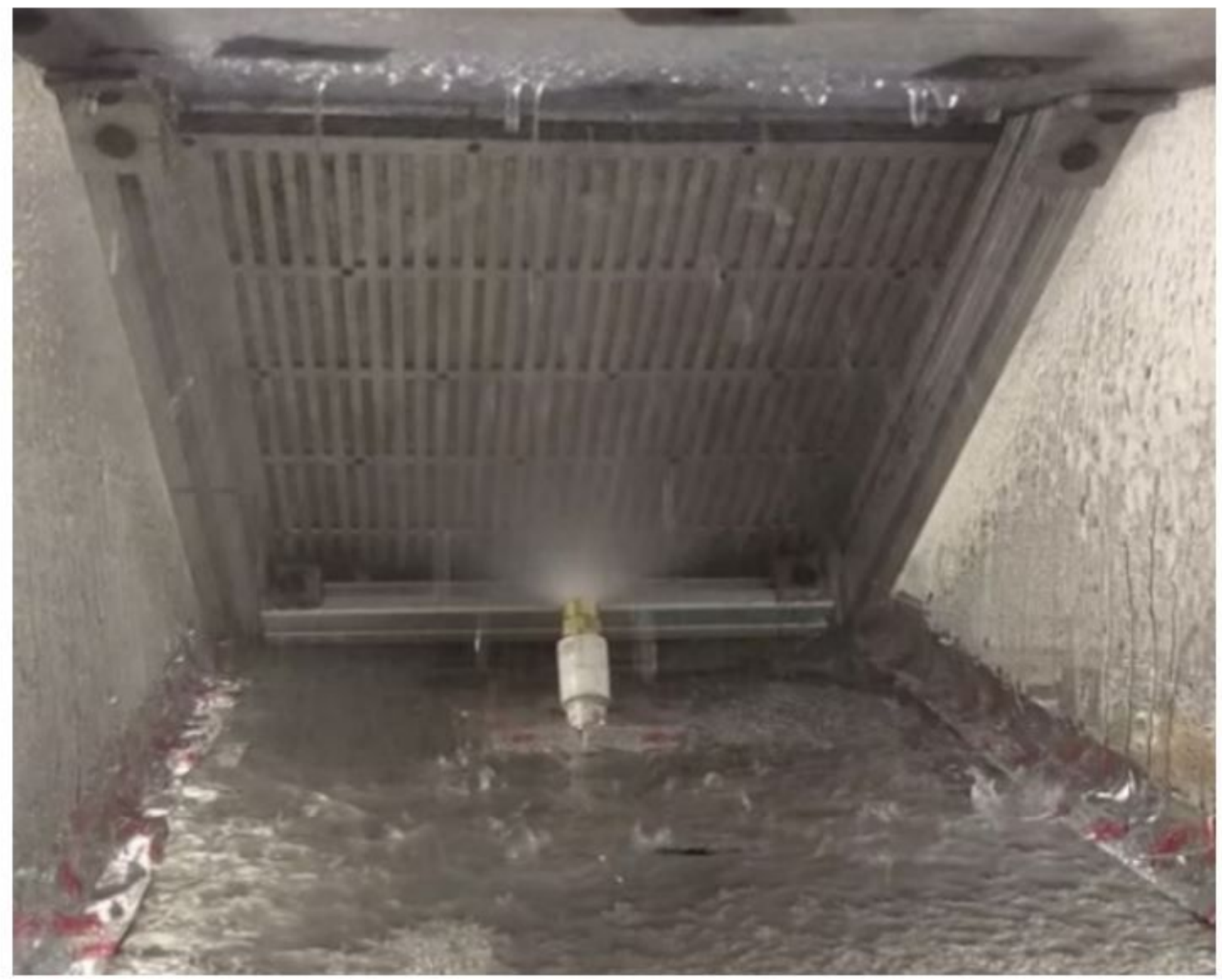

Figure 5

Filter installed in the duct 


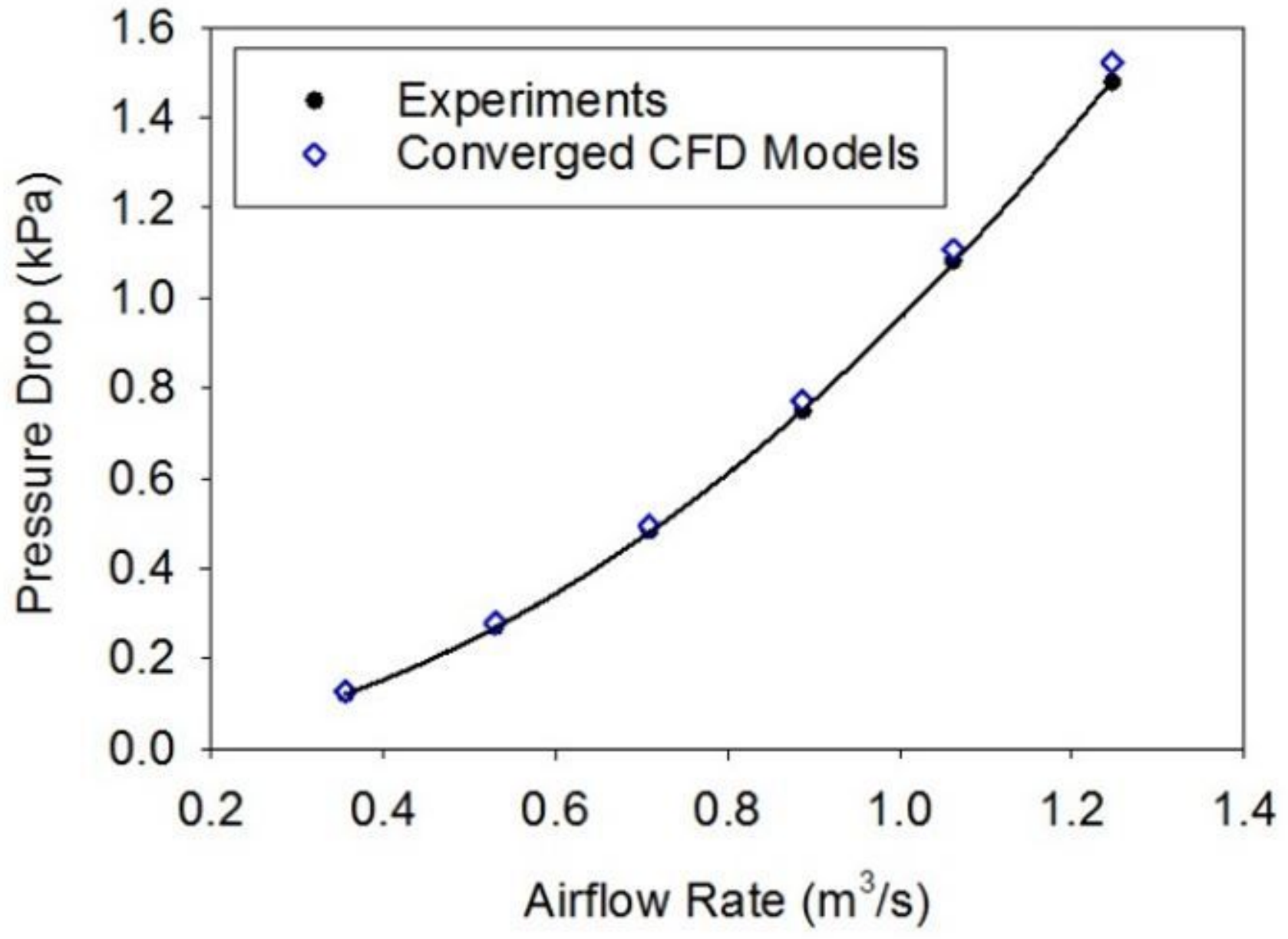

Figure 6

Converged CFD models and experiments 


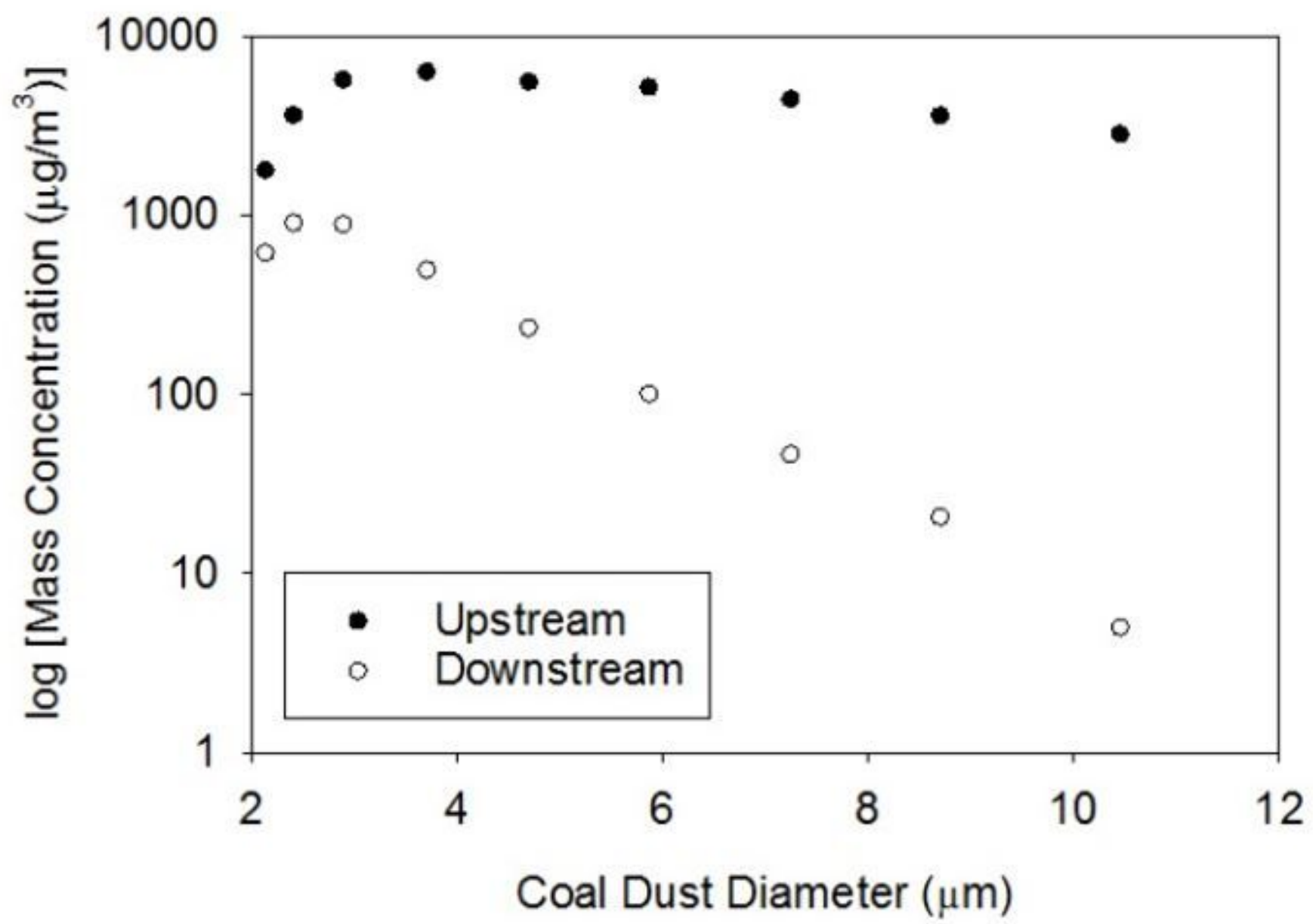

Figure 7

Dust concentration upstream and downstream of coal dust particles 


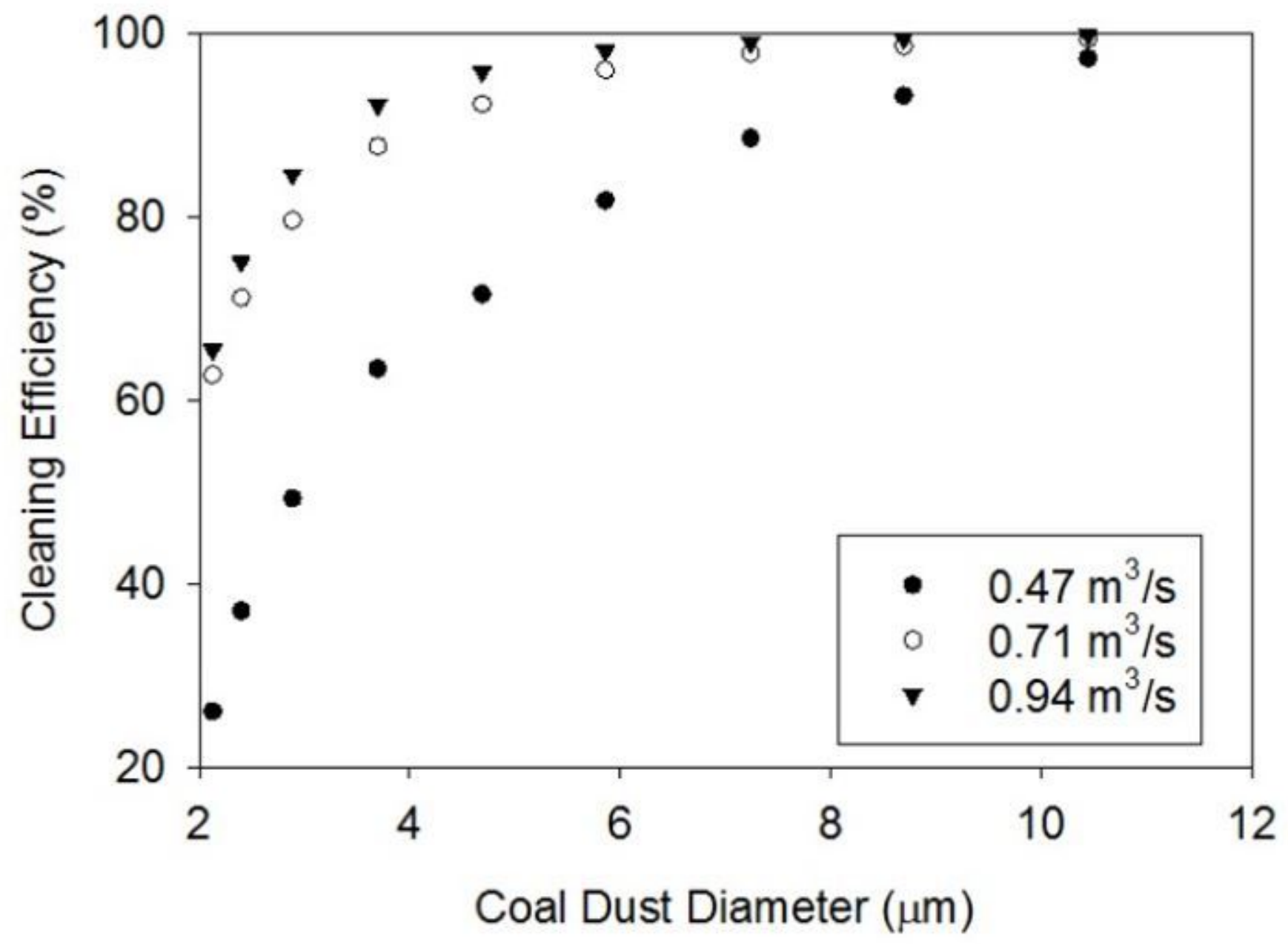

Figure 8

Coal dust cleaning efficiency of the filter 


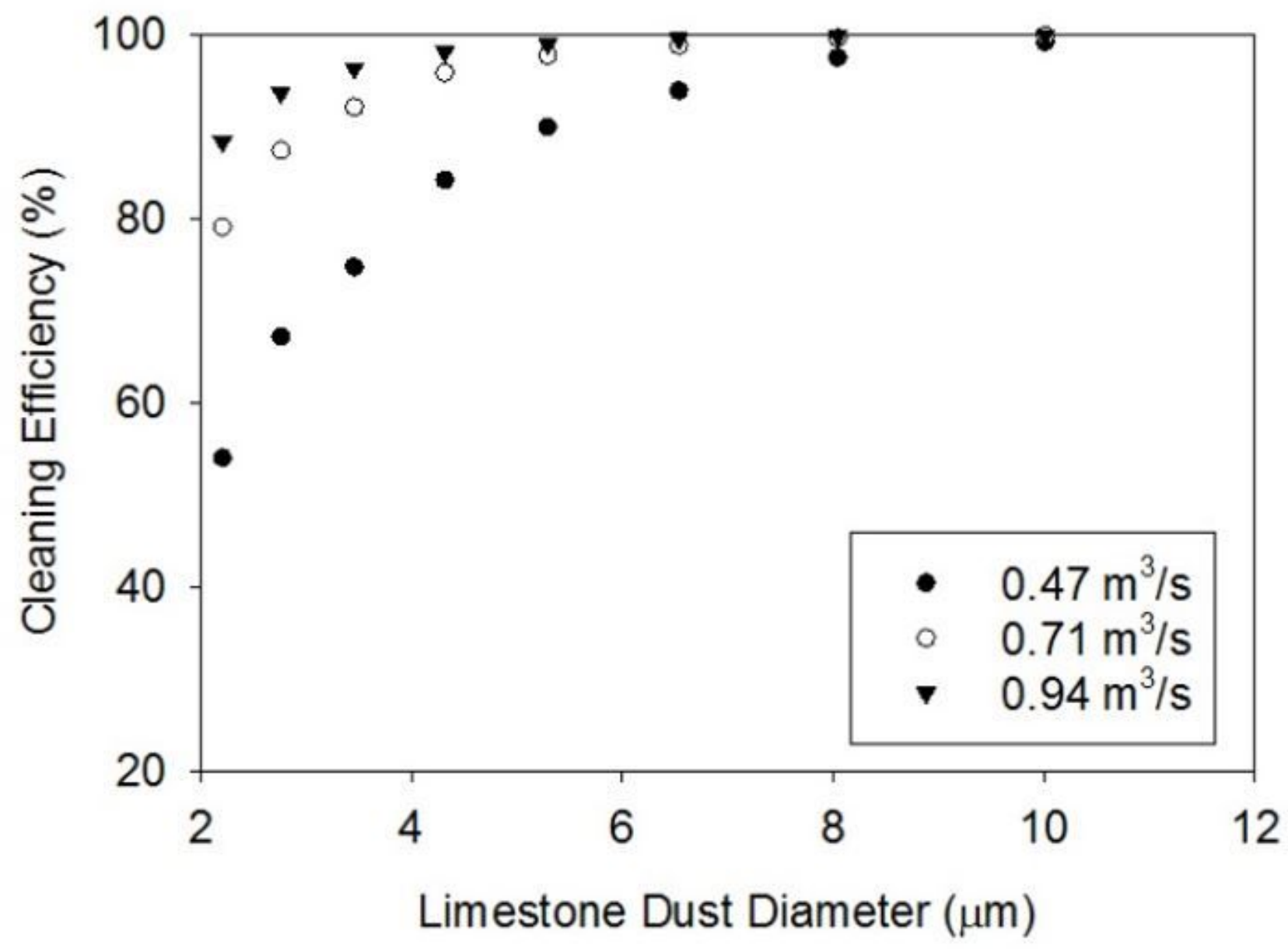

Figure 9

Limestone dust cleaning efficiency of the filter 


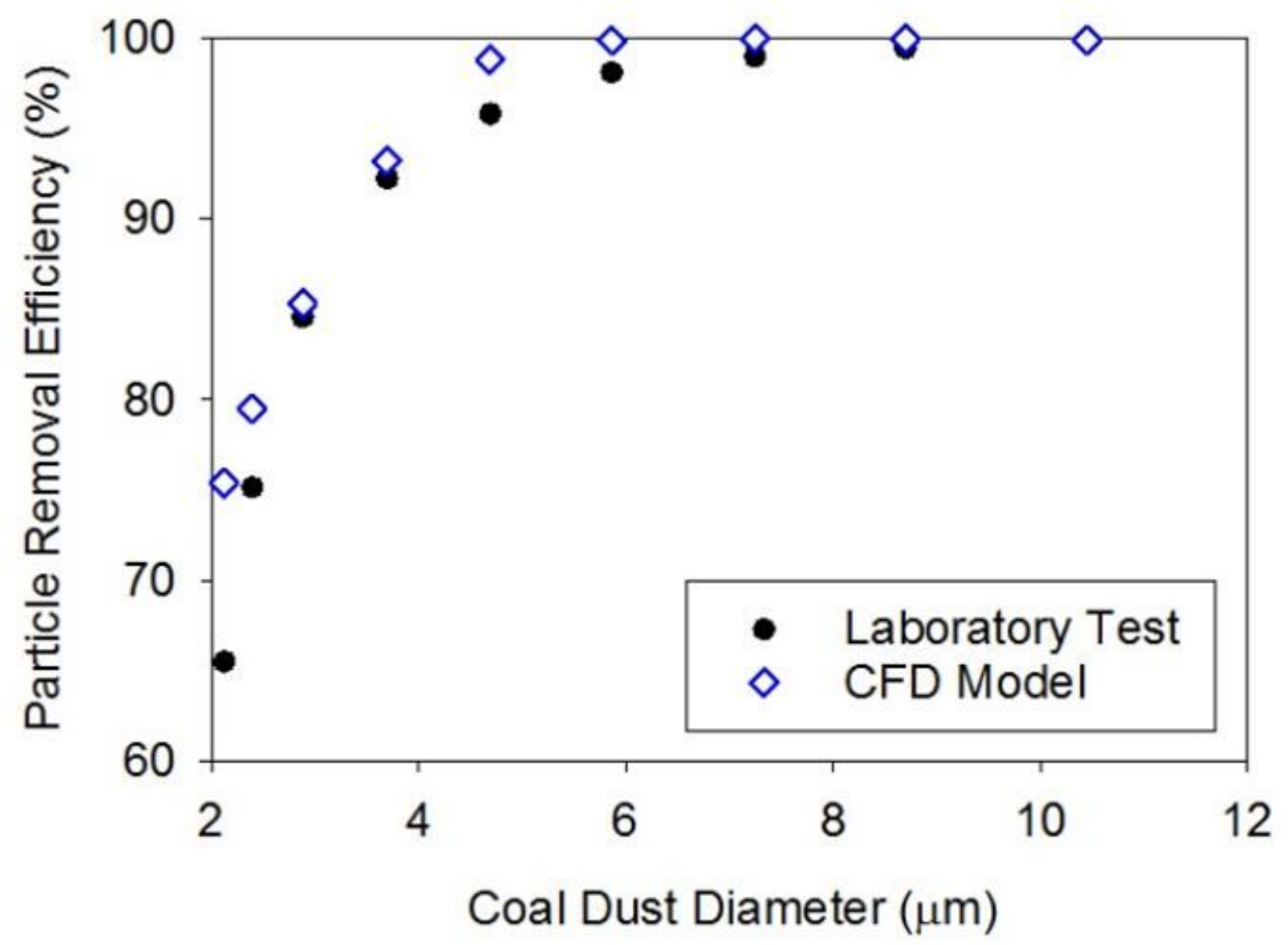

Figure 10

Comparision of cleaning efficiency of CFD models and laboratory test 


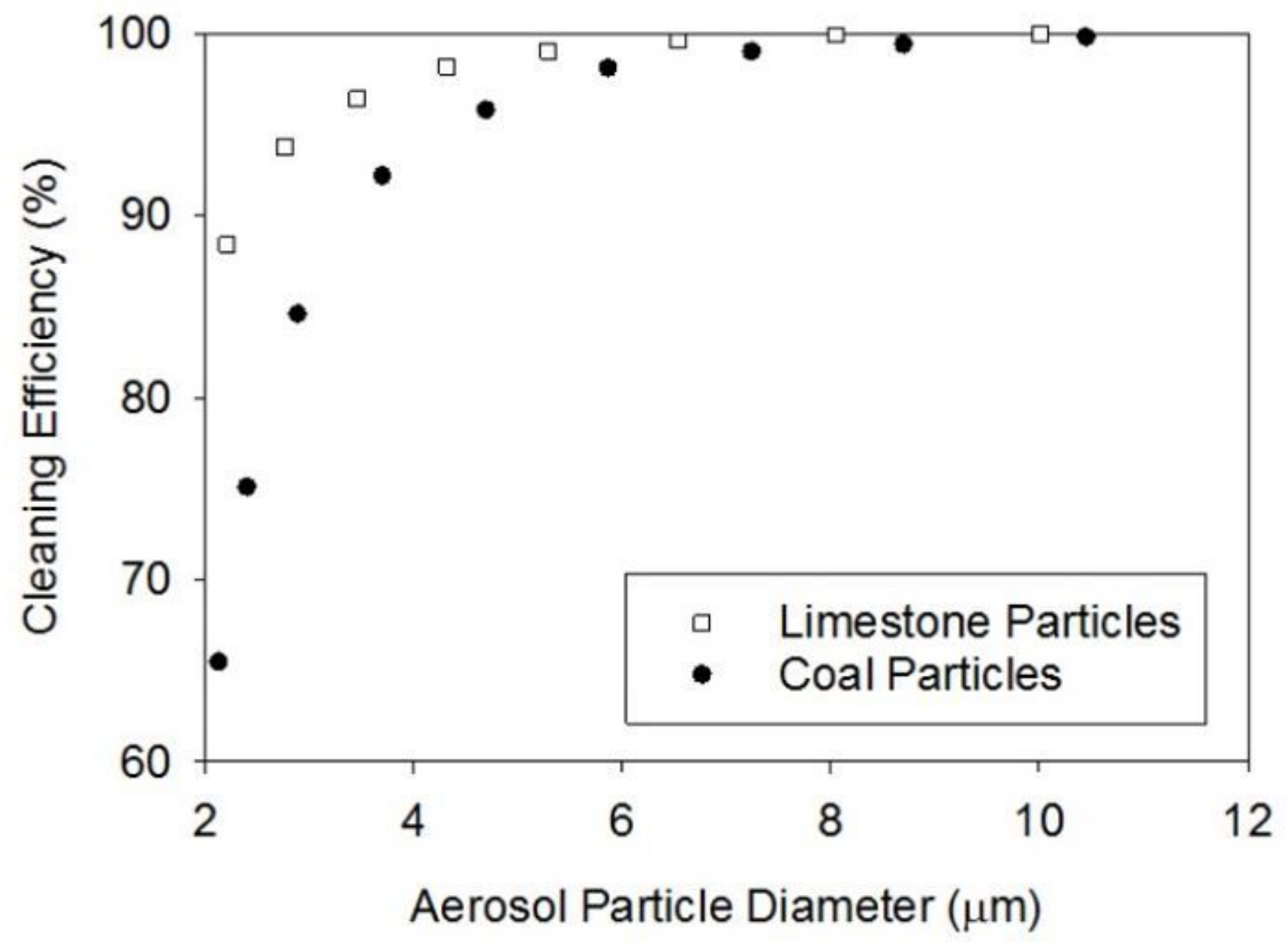

Figure 11

Comparision of cleaning efficiency of coal and limestone particles 